\title{
ANALISIS HUBUNGAN KUALITAS SITUS WEB DAN KUALITAS INFORMASI AKUNTANSI PERSEPSIAN
}

\author{
Juliwati Limbong \\ Fakultas of Ekonomika and Bisnis, Universitas Gadjah Mada \\ e-mail: lialimbo@ hotmail.com \\ Didi Achjari \\ Fakultas of Ekonomika and Bisnis, Universitas Gadjah Mada \\ e-mail: didi_a@ugm.ac.id
}

\begin{abstract}
One of the Investment Manager (IM) tasks in mutual fund is to arrange investment portfolio. To do so, IM relies on information that are available and can be accessed through the particular company's (share and obligation issuers) website. This study aims to investigate the impact of website quality on perceived accounting information quality, and also the variables (Perceived Information Asymmetric and Signal Credibility) that may moderate the relationship. In addition, the impact of perceived accounting information quality on accounting information trust is investigated. The questionnaire is administered to 87 asset management companies using purposive sample method. Responses from 33 companies then analyses using PLS based structural equation modeling (SEM). The results suggest that website quality positively influence perceived accounting information quality. Unfortunately, both moderating variables are not supported. Finally, the study shows that perceived accounting information quality affects accounting information trust.
\end{abstract}

Keywords: Web quality, perceived information asymmetric, signal credibility, perceived accounting information quality.

\begin{abstract}
Abstrak
Manager Investasi (MI) sebagai pengelola reksadana bertanggung jawab memilih portofolio investasi misal saham dan obligasi yang tersedia di pasar modal. Dalam pembentukan komposisi portofolio investasi, MI bergantung pada ketersediaan informasi emiten yang bisa diperoleh melalui situs web. Tujuan penelitian ini adalah untuk mengetahui sejauh mana pengaruh kualitas situs web emiten terhadap kualitas informasi akuntansi persepsian, dan meneliti adanya variabel pemoderasi hubungan kedua variabel tersebut. Selain itu penelitian ini juga ingin mengetahui sejauh mana pengaruh kualitas informasi akuntansi persepsian terhadap kepercayaan (trust) akan kualitas informasi akuntansi. Kuesioner disebar ke perusahaan managemen aset secara purposive sampling. Sampel penelitian ini adalah 87 perusahaan managemen aset yang terdaftar di Bursa Efek. Hasilnya adalah 33 perusahaan memberikan respon yang bisa dianalisis. Data diolah menggunakan PLS SEM. Hasil pengujian hipotesis menunjukkan Kualitas Situs Web berpengaruh positif terhadap Kualitas Informasi Akuntansi Persepsian. Sebaliknya, Asimetri Informasi Persepsian dan Kredibilitas Signal tidak terbukti memoderasi hubungan antara Kualitas Situs Web dan Kualitas Informasi Akuntansi Persepsian. Sebagai tambahan, penelitian ini menunjukkan bahwa Kualitas Informasi Akuntansi Persepsian mempengaruhi Kepercayaan (trust) para MI atas Kualitas Informasi Akuntansi emiten.
\end{abstract}

Kata kunci: Kualitas Situs Web, Asimetri Informasi Persepsian, Kredibilitas Signal, Kepercayaan akan Kualitas Informasi Akuntansi. 


\section{PENDAHULUAN}

Para Manajer Investasi (MI) mempunyai minat yang tinggi untuk mengelola dana dari masyarakat. Hal ini dibuktikan dengan jumlah MI yang telah beroperasi dan memiliki izin sebanyak 74 perusahaan (Otoritas Jasa Keuangan 2011). Dana kelolaan (Nilai Aktiva Bersih/Asset Under Management/AUM) reksadana yang dimiliki para investor menunjukkan pertumbuhan yang cukup signifikan. Dana kelolaan yang pada bulan Agustus 2003 sebesar $\mathrm{Rp} \mathrm{81,3} \mathrm{trilyun} \mathrm{(Herwidayatmo} \mathrm{2009)}$ telah meningkat menjadi Rp 209.791.886.186.252,00 per 30 Juni 2014.

Kendala yang dihadapi para MI dalam melakukan tugasnya antara lain akses informasi yaitu tidak tersedianya informasi setiap saat (Kotb dan Roberts 2011), serta prosedur on time transaction dengan masa akses yang terbatas. Kondisi tersebut dapat berkontribusi terhadap timbulnya resiko salah tafsir (misleading) informasi. Berdasarkan keadaan tersebut muncul kesepakatan di antara para ahli, agar dilakukan evaluasi secara berkesinambungan terhadap Sistem Pengendalian Internal (SPI) perusahaan (PCAOB 2007; COSO 2013). Dengan diterapkannya SPI yang memadai, akan dihasilkan informasi keuangan yang reliabel (Doyle, Ge, dan McVay 2007), karena diharapkan dapat memberi penjaminan penting terhadap kualitas data yang dihasilkan. Kegiatan pemantauan terhadap SPI, dapat dilakukan secara berkelanjutan (continuous online/real time) sebagaimana tugas yang diemban oleh Dewan Komisaris, yang dilaksanakan oleh Komite Audit Independen (Internal auditor). SPI melekat pada proses penyajian laporan keuangan, sehingga mempengaruhi kualitas informasi keuangan. Kelemahan SPI akan mempengaruhi kepercayaan para pengguna informasi (Malaescu dan Sutton 2015).

Bentuk usaha yang mengelola investasi secara khusus disebut dalam struktur pengaturan dan pengawasan Otoritas Jasa Keuangan (OJK) berupa kegiatan jasa keuangan sektor pasar modal (Undang-Undang No 21 Tahun 2011). Kegiatan jasa keuangan ini dikelola oleh MI dan dapat dibimbing oleh penasihat investasi, agar mempermudah dan menjamin keamanan berinvestasi bagi masyarakat luas (UU 8/1995). MI diharapkan memiliki keahlian dan profesionalitas yang tinggi, agar dapat mengembangkan usaha. Kegiatan pengelolaan investasi menuntut kemahiran bisnis dan penguasaan sistem teknologi informasi yang dilandasi kemampuan menilai integritas SPI perusahaan (Flowerday dan Solms 2005).

Saat ini para investor di pasar modal telah menggunakan sistem informasi dan komunikasi (Information and Communication Technology) agar dapat melakukan investasi setiap saat. Selain itu, mereka bisa mengganti dari satu pilihan investasi kepada pilihan investasi lainnya dengan cepat. Penggunaan teknologi informasi dapat memberikan keyakinan atas pengendalian sistem informasi, mengurangi bias informasi, memperhatikan keamanan informasi, serta memungkinkan untuk tersajinya informasi keuangan secara real time (Kotb dan Roberts 2011).

Perusahaan diharapkan dapat menyediakan profil keuangannya secara cepat ketika dibutuhkan dan berkelanjutan melalui penggunaan ICT berbasis web (e-business). ICT dapat mengintegrasikan kegiatan perusahaan baik secara internal maupun eksternal. ICT juga membantu para pelaku pasar modal untuk melakukan aktivitasnya tanpa harus mempertimbangkan jarak dan waktu bertransaksi.

Para MI sebagai pengelola investasi reksadana, mengakses informasi akuntansi emiten antara lain melalui situs web. Para MI sebagai pengguna informasi akuntansi memiliki perhatian pada ketepatan (accuracy) dan reliabilitas informasi (Nikolaou, Chymis, dan Evangelinos 2013; Vasarhelyi 1999). Lebih jauh, kualitas informasi tersebut dipengaruhi oleh keandalan sistem pengendalian internal (SPI) selama proses penyajian informasi keuangan (Doyle et al. 2007). Berdasarkan PCAOB 2007, evaluasi berkelanjutan terhadap SPI telah diterapkan pada beberapa negara Amerika (Vasarhelyi, Teeter, dan Krahel 2010).

Kotb dan Roberts (2011) mengatakan bahwa pengendalian diupayakan untuk meningkatkan accuracy informasi akuntansi, kepercayaan terhadap penggunaan sistem informasi real time, serta mengamankan informasi 
dari pihak yang tidak berkepentingan. Sebagai tambahan, perolehan informasi akuntansi melalui situs web, dipengaruhi oleh tingkat keamanan informasi (security), kecepatan tanggapan (Response Time), kesesuaian dengan penugasan (Fit to Task), dan keterhubungan antar informasi (Tailored Information).

Sebagai dasar penentuan keputusan investasi, MI membutuhkan informasi akuntansi emiten, baik yang seketika dan setiap saat (real time dan online) melalui situs web ataupun yang tahunan (laporan keuangan tahunan). Karena pembentukan portofolio investasi berlangsung lebih dari satu kali setiap tahun, dan karena laporan keuangan (audited report) hanya terbit dalam periode tahunan, maka MI dituntut untuk bisa menggunakan dan mempercayai informasi keuangan emiten yang tersedia secara online pada saat pembuatan keputusan investasi. Dalam hal ini, MI juga harus mampu menilai SPI emiten secara implisit untuk bisa mempercayai kualitas informasi akuntansi emiten yang disajikan secara online. Informasi akuntansi yang berkualitas adalah memiliki kriteria akurat, reliabel, verifiabel, tepat waktu dan dapat dipercaya (Loiacono, Watson, dan Goodhue 2007; Malaescu dan Sutton 2015; Nikolaou et al., 2013; Vasarhelyi 1999).

Penelitian terdahulu mengenai penggunaan situs web untuk keperluan komersial (Wells, Valacich, dan Hess 2011) dan untuk keperluan pengembangan penelitian sistem informasi (Loiacono et al. 2007) menunjukkan bahwa kualitas situs web mempengaruhi tingkat kepercayaan pengguna situs web. Penelitian ini merupakan pengembangan penelitian Wells et al. (2011) bertujuan untuk menguji sejauh mana Kualitas Situs Web mempengaruhi Kualitas Informasi Akuntansi Persepsian. Selain itu, penelitian ini dilakukan untuk mengetahui sejauh mana variabel Asimetri Informasi Persepsian dan Kredibilitas Sinyal mendera si hubungan antara Kualitas Situs Web dengan Kualitas Informasi Akuntansi Persepsian. Sebagai tambahan, penelitian ini juga menguji pengaruh persepsi Kualitas Informasi Akuntansi terhadap Kepercayaan akan Kualitas Informasi Akuntansi.

\section{TINJAUAN PUSTAKA DAN PERUMUSAN HIPOTESIS}

Dalam rangka untuk pengambilan keputusan, para pengguna informasi akuntansi akan berusaha mendapatkan informasi sebanyakbanyaknya, antara lain melalui situs web. Untuk itu, para pengguna informasi akuntansi memerlukan situs web yang berkualitas yang ditunjukkan dengan adanya fitur: informational fit-to-task, tailored information, trust, response time, ease of understanding, intuitive operations, visual appeal, innovativeness, emotional appeal, consistent image, on-line completeness, relative advantage (Loiacono et al. 2007; Wells et al. 2011; Vasarhelyi dan Halper 1991). Untuk menyajikan informasi akuntansi yang berkualitas seperti di atas secara real time dan online di dalam situs web, melibatkan penerapan sistem pengendalian internal (Davidson, Desai, dan Gerard 2013). Pengguna informasi akuntansi yang melakukan monitor secara real time dan online terhadap informasi keuangan perusahaan emiten, memerlukan kemampuan penilaian kegiatan pengendalian internal perusahaan (Ross 1986). Doyle et al. (2007) menyebutkan lingkungan pengendalian internal merupakan unsur dasar untuk menghasilkan kualitas pelaporan accrual yang baik. Dengan demikian kualitas situs web yang baik diduga akan berhubungan dengan kualitas informasi akuntansi persepsian. Berdasar uraian di atas, maka Hipotesis 1 adalah sebagai berikut:

H1: Kualitas Situs Web (KSW) berhubungan secara positif terhadap Kualitas Informasi Akuntansi Persepsian (KIAP).

Berdasarkan pemahaman Teori Keagenan (Jensen dan Meckling 1976), salah satu alasan audit atas laporan keuangan adalah karena adanya asimetri informasi antara manager (agent) dan pihak-pihak lain yang mempunyai kepentingan terhadap perusahaan (principal) yaitu pemilik, kreditur, investor dan lain-lain. Apabila asimetri informasi semakin kecil, maka akan berakibat pada menurunnya berbagai biaya, antara lain biaya modal dan biaya keagenan (biaya untuk meyakinkan keandalan/kualitas informasi akuntansi). Upaya untuk mengurangi asimetri informasi bisa 
dilakukan melalui evaluasi (monitoring) terhadap SPI dalam batas tertentu.

Hubungan antara kualitas situs website dan kualitas produk persepsian dimoderasi oleh keberadaan informasi asimetris (Wells et al. 2011). Dalam kondisi penjual memiliki informasi lebih banyak dibanding pembeli maka informasi asimetris akan muncul. Di transaksi secara daring (online), informasi asimetris muncul karena adanya prepurchase information scarcity and post-purchase information clarity (Kirmani and Akshay 2000). Dalam hal ini experience goods yang dijual secara online memiliki potensi yang tinggi akan terjadinya informasi asimetris. Sesuai Wells et al. (2011), dalam penelitian ini informasi asimetris juga diuji sebagai variabel pemoderasi. Dengan demikian, kehadiran informasi asimetris ini diduga akan mem pengaruhi hubungan antara Kualitas Situs Web dengan Kualitas Informasi Akuntansi Persepsian. Berikut adalah Hipotesis 2:

$\mathrm{H} 2$ : Asimetri Informasi Persepsian (AIP) memoderasi hubungan antara Kualitas Situs Web (KSW) dengan Kualitas Informasi Akuntansi Persepsian (KIAP).

Lebih lanjut, Teori Persinyalan (signaling theory) telah dipakai ketika ada asimetri informasi dalam pembuatan keputusan. Menurut Kirmani and Akshay (2000), konsumen akan mengandalkan sinyal ketika menilai kualitas suatu produk yang dengan informasi yang terbatas. Teori persinyalan yang banyak dipakai dalam bidang pemasaran juga dipakai di dalam konteks sistem infor- masi termasuk e-commerce. Penelitian $e$ commerce tentang kredibilitas sinyal sebagai variabel pemoderasi menunjukkan bahwa kredibilitas sinyal memperkuat hubungan kualitas website yang baik dengan persepsi kualitas produk (Wells et al. 2011). Dengan menggunakan argumen di atas, penelitian ini menambahkan variabel Kredibilitas Sinyal sebagai variabel pemoderasi dalam Hipotesis 3 sebagai berikut:

H3: Kredibilitas Sinyal (KS) memoderasi hubungan antara Kualitas Situs Web (KSW) dengan Kualitas Informasi Akuntansi Persepsian (KIAP).

Fogg dan Tseng (1999) menyatakan bahwa jika seseorang merasa yakin (trust) dengan sesuatu akan ditunjukkan dengan adanya perasaan positif yang berupa reliability, dependability dan confidence. Selanjutnya, dengan adanya perasaan positif tersebut maka sesuatu itu akan dipersepsikan sebagai berkualitas tinggi. Lebih lanjut, McKnight et al. (2002) dalam penelitiannya tentang toko daring (online store) yang terkait menyatakan bahwa kualitas persepsian mempengaruhi kepercayaan (trust). Penelitian berikut oleh Everard dan Galletta (2005) memperkuat temuan McKnight, Choudhury, dan Kacmar (2002) yaitu kualitas toko daring persepsian mempengaruhi kepercayaan terhadap toko daring tersebut. Dari uraian di atas, dirumuskan hipotesis:

H4: Kualitas Informasi Akuntansi Persepsian (KIAP) berpengaruh positif terhadap Kepercayaan akan Kualitas Informasi Akuntansi (KIA).

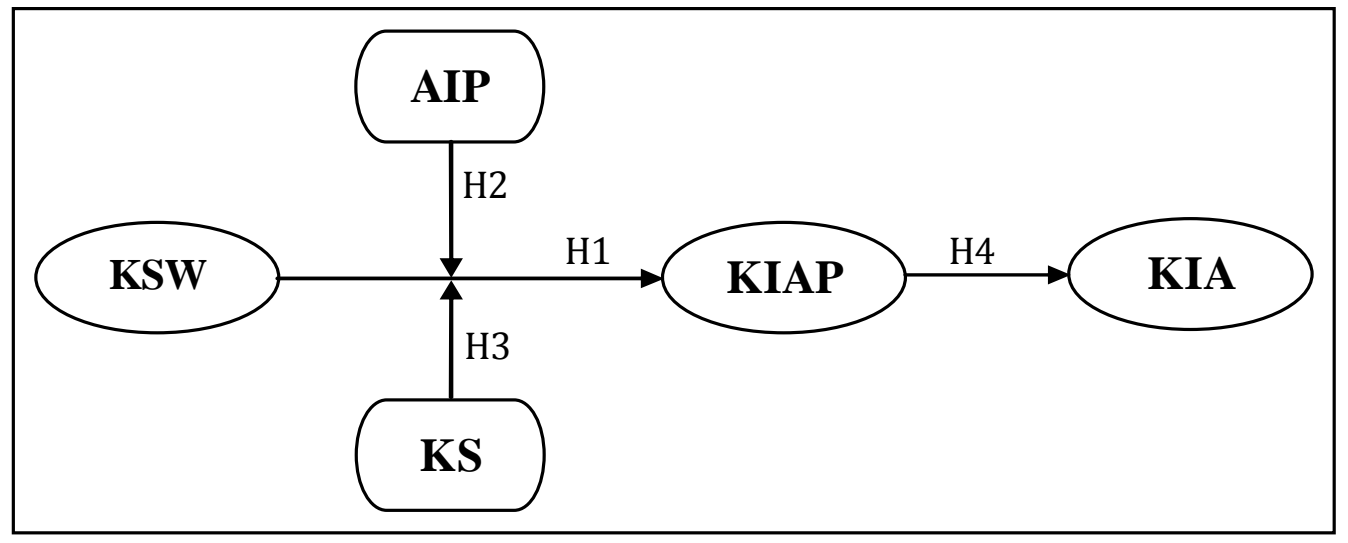

Gambar 1: Model Penelitian 
Keterangan :

$$
\begin{aligned}
\mathrm{KSW} & =\text { Kualitas Situs Web } \\
\mathrm{AIP} & =\text { Asimetri Informasi Persepsian } \\
\mathrm{KS} & =\text { Kredibilitas Signal } \\
\mathrm{KIAP} & =\text { Kualitas Informasi Akuntansi Per- } \\
& \text { sepsian } \\
\mathrm{KIA}= & \text { Kepercayaan akan Kualitas } \\
& \text { Informasi Akuntansi }
\end{aligned}
$$

\section{METODA PENELITIAN}

Pengumpulan data dilakukan menggunakan survei kuesioner karena data berupa opini individu (Hartono 2008). Metode penentuan sampel menggunakan purposive sampling (pemilihan sampel berdasarkan kriteria tertentu sesuai karakteristik yang dikehendaki). Karakteristik sampel yaitu: (1) Para manager investasi dan penasihat investasi yang terdaftar pada Bapepam-LK (OJK), yaitu memiliki ijin beroperasi di pasar modal Indonesia; (2) Pernah mengakses data dari sumber berbasis Enterprise Resource Planning (ERP) systems seperti SAP, Oracle, PeopleSoft dan generic industry software seperti Funds Radar, atau melalui sistem data yang menggunakan Structured Query Language (SQL).

Sampel yang dipilih dalam penelitian ini berjumlah 87 perusahaan yang terdaftar di Bursa Efek Indonesia (BEI). Data deskriptif menunjukkan bahwa 67 perusahaan aktif mengelola dana investasi sampai dengan Juni 2014 dengan nilai sebesar Rp. 209,7 T. Perusahaan yang tidak mempunyai mutasi pengelolaan investasi sejak Januari 2012 sampai Juli 2014 berjumlah 20 perusahaan. Kuesioner dikirimkan kepada sampel 87 perusahaan. Pada akhir tenggat waktu, dari 87 kuesioner yang dikirim, kuesioner yang bisa diproses untuk analisis data adalah 33 buah, dengan rincian di Tabel 1. Jumlah respon 33 buah dianggap memadai untuk dianalisis dengan menggunakan PLS dengan rule of thumb 10 kali item dalam konstruk yang paling kompleks (Gefen, Straub, dan Boudreau 2000). Dalam hal ini konstruk yang paling kompleks memiliki item pertanyaan sebanyak 3 buah.

Tabel 1: Kuesioner dan Response Rate

\begin{tabular}{lc}
\hline Kuesioner dikirim & 87 \\
MI tidak beroperasi (tutup) & 20 \\
Kuesioner tidak kembali & 29 \\
Kuesioner kembali & 38 \\
Kuesioner tidak lengkap & 5 \\
Kuesioner diolah untuk analisis & 33 \\
Response Rate & $37,93 \%$ \\
\hline
\end{tabular}

Data demografi responden bisa dilihat di Tabel 2. Klasifikasi para responden menunjukkan bahwa $84,85 \%$ responden adalah pria. Mayoritas responden $(51,50 \%)$ berusia antara 23 sampai 30 tahun. Selain itu, mayoritas responden $(69,69 \%)$ juga memiliki pengalaman kerja antara 1-5 tahun. Sebagai tambahan, pendidikan responden yang Sarjana S1 sebanyak 69,69\% dan S2 sejumlah 27,27\%.

Penelitian ini menggunakan variabel Computer Playfulness (CP) sebagai variabel kontrol. Berdasarkan distribusi data sampel menunjukkan $72,72 \%$ untuk CP1 (kemudahan) dan 60,60\% untuk CP2 (fleksibilitas). Dengan demikian, para MI menganggap bahwa informasi yang tersedia melalui situs web dapat meningkatkan kemudahan dan fleksibilitas kerja mereka.

Tabel 2: Demografi Responden (Manajer Investasi)

\begin{tabular}{llcc}
\hline \multicolumn{1}{c}{ Demografi } & \multicolumn{1}{c}{ Klasifikasi } & Jumlah Responden & Prosentase \\
\hline \multirow{2}{*}{ Kelamin } & Pria & 28 & $84,85 \%$ \\
& Wanita & 5 & $15,15 \%$ \\
\multirow{4}{*}{ Usia } & $23-30$ & 17 & $51,50 \%$ \\
& $31-40$ & 8 & $24,25 \%$ \\
\multirow{5}{*}{ Pengalaman Kerja } & $41-56$ & 8 & $24,25 \%$ \\
& $1-5$ & 23 & $69,69 \%$ \\
\multirow{5}{*}{ Pendidikan } & $6-10$ & 9 & $27,27 \%$ \\
& $>10$ & 1 & $3,04 \%$ \\
& S 1 & 23 & $69,69 \%$ \\
& S II & 9 & $27,27 \%$ \\
\hline
\end{tabular}




\section{HASIL DAN PEMBAHASAN}

Hasil uji keandalan terhadap variabel Kualitas Situs Web (KSW), Asimetri Informasi Persepsian (AIP), Kredibilitas Signal (KS), Kualitas Informasi Akuntansi Persepsian (KIAP), dan Kepercayaan akan Kualitas Informasi Akuntansi (KIA) menunjukkan Cronbach $\alpha>0,6$ serta composite reliability $>0,7$ (lihat Tabel 3 di bawah).Dengan demikian keseluruhan kon struk dalam penelitian ini andal (Hair et al. 2010). Lebih jauh, uji Validitas Konvergen dilakukan dengan mengukur AVE dan communality. AVE dan communality untuk semua variabel menunjukkan skor $>0,5$. Hal ini menunjukkan bahwa indikator masing-masing konstruk yang masuk ke variabel lainnya kurang dari 50\%, sehingga indikator-indikator tersebut konvergen pada konstruk yang dimaksud (Hartono 2011). Sebagai tambahan, karena faktor loading untuk indikator KswRT3, KswSC1, KS3 dan CP3 lebih kecil dari 0,5 maka dilakukan eliminasi terhadap indikator tersebut.

Uji validitas diskriminan dilakukan dengan mengukur skor cross loading. Tabel 4 menampilkan hasil cross loading item-item yang di dalam variabel KSW, AIP, KS, KIAP dan KIA. Item-item tersebut menunjukkan skor loading lebih tinggi pada konstruknya sendiri.

Tabel 3: Hasil Uji AVE, Composite Reliability, R Square dan Cronbach Alpha

\begin{tabular}{lcccccc}
\hline Konstruk & AVE $>0,5$ & $\begin{array}{c}\text { Composite } \\
\text { Reliability } \\
>0,7\end{array}$ & $\begin{array}{c}\text { R-Square } \\
<1\end{array}$ & $\begin{array}{c}\text { Cronbac } \\
\text { h Alpha } \\
>0,6\end{array}$ & $\begin{array}{c}\text { Communality } \\
>0,5\end{array}$ & $\begin{array}{c}\text { Redundancy } \\
<1\end{array}$ \\
\hline KSW & 0,5521 & 0,924 & 0 & 0,9076 & 0,5521 & 0 \\
AIP & 0,6558 & 0,8486 & 0 & 0,7534 & 0,6558 & 0 \\
KS & 0,9226 & 0,9598 & 0 & 0,9166 & 0,9226 & 0 \\
KIAP & 0,711 & 0,8805 & 0,5528 & 0,7972 & 0,711 & 0,1128 \\
KIA & 0,8133 & 0,9284 & 0,112 & 0,9018 & 0,8133 & 0,038 \\
CP & 0,9198 & 0,9582 & 0 & 0,9207 & 0,9198 & 0 \\
KSW * AIP & 0,7306 & 0,9878 & 0 & 0,9872 & 0,7306 & 0 \\
KSW * KS & 0,8101 & 0,9884 & 0 & 0,9876 & 0,8101 & 0 \\
\hline
\end{tabular}

Tabel 4: Cross Loading

\begin{tabular}{rrrrrrr}
\hline & \multicolumn{1}{c}{ KSW } & \multicolumn{1}{c}{ AIP } & \multicolumn{1}{c}{ KS } & \multicolumn{1}{c}{ KIAP } & \multicolumn{1}{c}{ KIA } & \multicolumn{1}{c}{ CP } \\
\hline KswFT1 & $\mathbf{0 , 8 8 9 7}$ & 0,5178 & 0,4332 & 0,6705 & 0,1101 & 0,2675 \\
KswFT2 & $\mathbf{0 , 8 6 5 3}$ & 0,5642 & 0,308 & 0,5662 & 0,004 & 0,1574 \\
KswFT3 & $\mathbf{0 , 7 2 9 6}$ & 0,4308 & 0,2922 & 0,4587 & 0,0278 & 0,1249 \\
KswRT1 & $\mathbf{0 , 6 6 5 8}$ & 0,3984 & 0,2515 & 0,4909 & $-0,0086$ & 0,1035 \\
KswRT2 & $\mathbf{0 , 7 4 4 5}$ & 0,4146 & 0,2367 & 0,5671 & $-0,0319$ & 0,1945 \\
KswSC2 & $\mathbf{0 , 7 4 3 1}$ & 0,3368 & 0,4245 & 0,5931 & 0,2196 & 0,1853 \\
KswSC3 & $\mathbf{0 , 6 3 1 2}$ & 0,4572 & 0,2754 & 0,6126 & 0,0596 & 0,1397 \\
KswTI1 & $\mathbf{0 , 6 0 0 1}$ & 0,2559 & 0,1132 & 0,3601 & 0,1558 & 0,3269 \\
KswT1 & $\mathbf{0 , 7 5 7 9}$ & 0,4998 & 0,272 & 0,5397 & 0,0733 & 0,2946 \\
KswT13 & $\mathbf{0 , 7 5 2 2}$ & 0,3832 & 0,1864 & 0,4711 & 0,0171 & 0,2312 \\
Aip1 & 0,609 & $\mathbf{0 , 9 4 4 3}$ & 0,1744 & 0,5578 & 0,0057 & $-0,0276$ \\
Aip2 & 0,4464 & $\mathbf{0 , 7 9 1 8}$ & 0,2857 & 0,2928 & 0,0149 & 0,0668 \\
Aip3 & 0,2326 & $\mathbf{0 , 6 7}$ & $-0,0964$ & 0,1802 & 0,1262 & 0,013 \\
Ks1 & 0,3914 & 0,2364 & $\mathbf{0 , 9 6 6 4}$ & 0,3703 & 0,0483 & 0,2185 \\
Ks2 & 0,3562 & 0,1119 & $\mathbf{0 , 9 5 4 6}$ & 0,3193 & $-0,0629$ & 0,2684 \\
Kiap1 & 0,6491 & 0,3506 & 0,4314 & $\mathbf{0 , 8 8 2 6}$ & 0,298 & 0,344 \\
Kiap2 & 0,5049 & 0,4715 & 0,1083 & $\mathbf{0 , 8 1 4}$ & 0,2989 & 0,4623 \\
Kiap3 & 0,6807 & 0,4272 & 0,3363 & $\mathbf{0 , 8 3 1 4}$ & 0,1682 & 0,2224 \\
Kia1 & $-0,0013$ & 0,0395 & $-0,0476$ & 0,2634 & $\mathbf{0 , 9 4 6 8}$ & 0,2429 \\
Kia2 & 0,1635 & 0,0344 & 0,0442 & 0,3369 & $\mathbf{0 , 9 5 7 7}$ & 0,2695 \\
Kia3 & $-0,0176$ & $-0,0127$ & $-0,0628$ & 0,0414 & $\mathbf{0 , 7 9 1 3}$ & 0,0749 \\
CP1 & 0,2903 & 0,0842 & 0,25 & 0,3782 & 0,1542 & $\mathbf{0 , 9 3 4 7}$ \\
CP2 & 0,2435 & $-0,0328$ & 0,2393 & 0,386 & 0,2973 & $\mathbf{0 , 9 8 2 9}$ \\
\hline
\end{tabular}


Tabel 5: Hasil Output SEM (Path Coefficient)

\begin{tabular}{llrrrrr}
\hline Hipotesis & \multicolumn{1}{c}{ Jalur } & $\begin{array}{c}\text { Sample } \\
\text { Mean }\end{array}$ & St Dev & $\begin{array}{c}\text { St } \\
\text { Error }\end{array}$ & $\begin{array}{c}\text { T } \\
\text { Statistic }\end{array}$ & Hasil \\
\hline Hipotesis 1 & KSW $\rightarrow$ KIAP & 0,849 & 0,1384 & 0,1384 & 6,0541 & Terdukung \\
Hipotesis 2 & KSW*AIP $\rightarrow$ KIAP & $-0,2067$ & 0,2224 & 0,2224 & 0,737 & Tidak \\
Hipotesis 3 & KSW*KS $\rightarrow$ KIAP & $-0,2513$ & 0,2912 & 0,2912 & 0,8913 & Tidak \\
Hipotesis 4 & KIAP $\rightarrow$ KIA & 0,2204 & 0,0975 & 0,0975 & 2,3958 & Terdukung \\
\hline *p<0,05.**p<0,01 ; & & & & & & \\
$n s=$ tidak signifikan (not significant) & & & &
\end{tabular}

Hasil analisa data yang ada di Tabel 4 dan Tabel 5 menunjukkan hasil yang bervariasi yaitu 2 hipotesis terdukung dan 2 hipotesis lainnya tidak terdukung. Kualitas Situs Web berpengaruh secara signifikan positif terhadap Kualitas Informasi Akuntansi Persepsian ( $\mathrm{p}<0,01$ dan t-statistik 6,0541). Dengan demikian, Hipotesis 1 terdukung. Selanjutnya, Asimetri Informasi Persepsian (AIP) tidak terbukti memoderasi hubungan antara Kualitas Situs Web dengan Kualitas Informasi Akuntansi Persepsian (t-statistik 0,737). Dengan demikian Hipotesis 2 tidak terdukung. Uji statistik yang hasilnya juga tidak signifikan adalah Hipotesis 3. Kredibilitas Signal (KS) tidak terbukti memoderasi hubungan antara Kualitas Situs Web dengan Kualitas Informasi Akuntansi Persepsian ( $\mathrm{t}$ statistik 0,8913). Terakhir, uji statistik pada Hipotesis 4 menunjukkan bahwa Kualitas Informasi Akuntansi Persepsian berpengaruh secara signifikan positif terhadap Kepercayaan akan Kualitas Informasi Akuntansi ( $\mathrm{p}<0,05$, dengan t statistik 2,3958).

\section{SIMPULAN}

Kualitas Situs Web (KSW) menunjukkan hubungan signifikan terhadap Kualitas Informasi Akuntansi Persepsian (KIAP) pada Hipotesis 1. Hal ini ditunjukkan oleh $\mathrm{p}<0,01$ pada $\mathrm{t}=6,0541$. Dengan demikian, hasil ini mendukung penelitian yang telah dilakukan pada pengguna situs web untuk keperluan komersial (Wells et al. 2011) dan keperluan pengembangan penelitian sistem informasi (Loiacono et al. 2007). Konstruk Kualitas Situs Web (KSW) berupa Informational Fit to Task, Response Time, Security, dan Tailored
Information dalam penelitian Wells et al. (2011) dan dalam penelitian Loiacono et al. (2007) mempengaruhi persepsi pengguna informasi (para MI). Para MI tersebut berupaya mendapatkan informasi akuntansi melalui situs web.

Dua variabel pemoderasi dalam model penelitian ini ternyata tidak berhasil mendukung Hipotesis 2 dan Hipotesis 3. Hubungan antara Kualitas Situs Web (KSW) dengan Kualitas Informasi Akuntansi Persepsian (KIAP), tidak terbukti dimoderasi oleh Asimetri Informasi Persepsian (AIP). Hal ini ditunjukkan oleh $\mathrm{t}$ statistik $=0,737$. Dengan demikian Hipotesis 2 tidak terdukung. Selanjutnya, pengaruh Kualitas Situs Web (KSW) terhadap Kualitas Informasi Akuntansi Persepsian (KIAP), tidak terbukti dimoderasi oleh Kredibilitas Signal (KS). Hal ini ditunjukkan oleh $\mathrm{t}$ statistik $=0,8913$. Hasil ini menunjukkan bahwa Hipotesis 3 juga tidak terdukung.

Pengaruh Kualitas Informasi Akuntansi Persepsian (KIAP) terhadap Kepercayaan akan Kualitas Informasi Akuntansi (KIA) menunjukkan signifikansi $\mathrm{p}<0,05$ pada $\mathrm{t}=2$,3958. Dengan demikian Hipotesis 4 terdukung. Hasil ini menunjukkan bahwa para MI melakukan investasi atas surat berharga emiten berdasarkan kepercayaan (trust) atas informasi akuntansi ketika mereka mengakses secara real time. Flowerday dan Solms (2005) yang mencatat bahwa proses penyajian laporan keuangan mempengaruhi kepercayaan para pengguna informasi akuntansi.

Para MI diharapkan memiliki kompetensi melakukan analisa laporan keuangan dan mengumpulkan informasi relevan lainnya melalui situs web. Mereka juga diharapkan 
memiliki pengetahuan bisnis dan kemahiran teknis (pengetahuan hibrid) mengenai informasi teknologi (Hartono 2009). Lebih lanjut, mereka juga diharapkan mempunyai peran semu (pseudo) sebagai auditor untuk melakukan review SPI emiten.

\section{DAFTAR REFERENSI}

Committee of Sponsoring Organizations of the Treadway Commission (COSO). 2013. Internal Control-Integrated Framework. http://www.coso.org/documents/inter nal\%20controlintegrated\%20framework.pdf (diakses 7 Februari 2014).

Davidson, B.I., N. K. Desai, dan G. J. Gerard. 2013. The effect of continuous auditing on the relationship between internal audit sourcing and the external auditor's reliance on the internal audit function. Journal of Information Sistems 27 (1): 41-59.

Doyle, J.T., W. Ge, dan S. McVay. 2007. Accruals quality and internal control over financial reporting. The Accounting Review 82 (5): 11411170.

Everard, A., dan D. F. Galletta. 2005. How presentation flaws affect perceived site quality, trust, and intention to purchase from an online store. Journal of Management Information Systems 22 (3): 55-95

Flowerday, S., dan R. V. Solms. 2005. Real time information integrity $=$ system integrity + data integrity + continuous assurances. Computers and Security 24 (8): 604-613.

Fogg, B.J., dan H. Tseng. 1999. The elements of computer credibility. The ACM CHI Conference on Human Factors in Computing Systems, Pittsburgh USA: 15-20.

Gefen, D., D. Straub, dan M. C. Boudreau. 2000. Structural equation modeling and regression: Guidelines for research practice. Communications of the Association for Information Systems 4.

Hair, JF., W. C. Black, B. J. Babin, dan R. E. Anderson. 2010. Multivariate data analysis, seventh edition. New Jersey: Prentice Hall.

Hartono, J. 2008. Metodologi penelitian sistem informasi. Yogyakarta: Andi Offset.

Hartono, J. 2009. Sistem teknologi informasi. Yogyakarta: Andi Offset.

Hartono, J. 2011. Konsep dan aplikasi structural equation modeling berbasis varian dalam penelitian bisnis. Yogyakarta: UPP STIM YKPN

Herwidayatmo. 2009. Peranan pasar modal dalam memperkuat eksistensi keuangan negara pasca-UU No 8/1995 tentang pasar modal, dalam era baru kebijakan fiskal pemikiran, konsep, dan implementasi. Kompas.com (diakses 13 Desember 2013).

Jensen, M.C., dan W. H. Meckling. 1976. Theory of the firm: Managerial behavior, agency costs and ownership structure. Journal of Financial Economics 3 (4): 305-360.

Kirmani, A. dan R. R. Akshay. 2000. No pain, no gain: A critical review of the literature on signaling unobservable product quality. Journal of Marketing 64 (2): 66-79.

Kotb, A. dan C. Roberts. 2011. The impact of e-business on the audit process: An investigation of the factors leading to change. International Journal of Auditing 15 (2): 150-175.

Loiacono, E.T., R. T. Watson., dan D. L. Goodhue. 2007. Webqual: An instrument for consumer evaluation of web sites. International Journal of Electronic Commerce 11 (3): 51-87.

Malaescu, I., dan S. G. Sutton. 2015. The reliance of external auditors on 
internal audit's use of continuous audit. The Journal of Information Systems 29 (1): 95-114.

McKnight, D.H., V. Choudhury, dan C. Kacmar. 2002. Developing and validating trust measures for ecommerce: An integrative typology. Information Systems Research 13 (3): 334-359.

Nikolaou, IE., A. Chymi, dan K. Evangelinos. 2013. Environmental information, asymmetric information, and financial markets: A game-theoretic approach. Environmental Modeling Assessment 18 (6): 615-628.

Otoritas Jasa Keuangan. 2011. Daftar reksa dana yang efektif pada tahun 2010. http://aria.bapepam.go.id/reksadana/fi les/berita/PPRD\%20EFEKTIF\%2020 10-2011.pdf (diakses 15 Februari 2014).

Public Company Accounting Oversight Board (PCAOB). 2004. An audit of internal control over financial reporting performed in conjunction with an audit of financial statements. http://pcaobus.org/Rules/Rulemaking /Docket008/2004-0309_Release_2004-001-all.pdf (diakses 7 Februari 2014).

Public Company Accounting Oversight Board (PCAOB). 2007. Proposed auditing standard: An audit of internal control over financial Reporting that is integrated with an audit of financial statement.

http://pcaobus.org/Rules/Rulemaking /Docket\%20021/2007-0612_Release_No_2007-005A.pdf (diakses 7 Februari 2014).

Ross, F.E. (1986). Internal control and audit of real time digital systems, Journal of Accountancy 119 (4): 46-56.

Vasarhelyi, M. A., dan F. B. Halper. 1991. The continuous audit of online systems. Journal of Practice and Theory 10 (1): 110-125.

Vasarhelyi, M. A. 1999. Towards an intelligent audit: Online reporting, online audit, and other assurance services. New Jersey: Rutgers University, Newark.

Vasarhelyi, M. A., R. A. Teeter, dan J. P. Krahel. 2010. Audit education and the real time economy. Accounting Education 25 (3): 405-423.

Wells, J.D., J. S. Valacich, dan T. J. Hess. 2011. What signal are you sending? How website quality influences perceptions of product quality and purchase intentions. MIS Quarterly 35 (2): 373-396. 